\title{
From children's literature to sustainability science and youth in scientific research
}

\author{
Quan-Hoang Vuong
}

SDAG Lab, Centre for Interdisciplinary Social Research (ISR)

Phenikaa University, Yen Nghia, Ha Dong District, Hanoi 100803, Vietnam

\begin{abstract}
As the future of human development increasingly hinges on the need for sustainable education and science, this essay re-examines the imminent threats to humankind and the relevance of achieving the United Nations' Sustainable Development Goals (SDGs) to science-technology research among today's young scientists. It also discusses some socio-political and economic challenges to achieving sustainability and argues that developing sustainability science is difficult but not impossible. The hope lies in our current efforts to build productive and creative scientific communities through nurturing youth engagement with science and the scientific mindset.
\end{abstract}

Keywords: sustainability science; youth engagement; scientific mindset

Version: \#4; December 1, 2019

A contribution paper for

ASEAN Conference for Young Scientists 2019
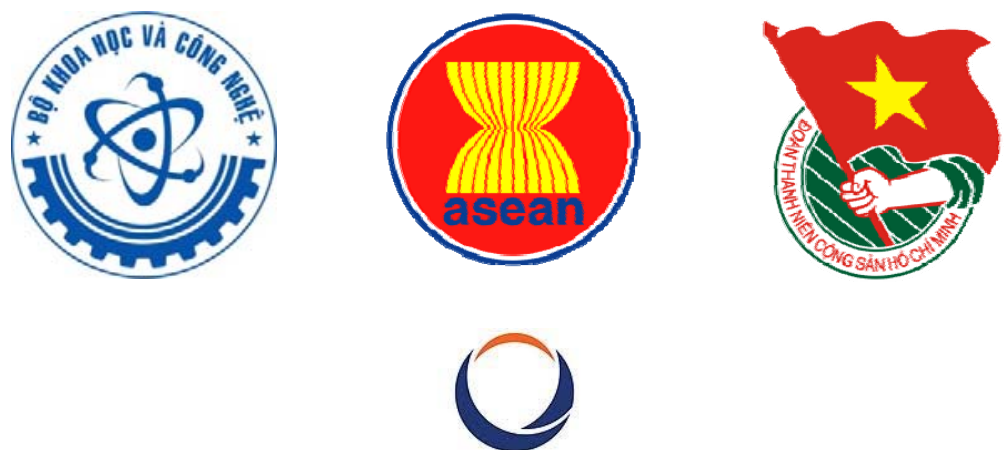

PHFNIKAA

UNIVERSITY

Hanoi, December 2, 2019. 


\section{Introduction}

In a children's book titled "Trong Rùng Dẻ Gai"1 (lit. "In the Hazelnut Forest") written in 1974 by the late Vietnamese writer Nguyen Thi Ngoc Tu (1942-2013), the mystifying forests and natural splendor of the northern province of Quang Ninh were brought to life. The book, despite having been written during the Resistance War against America and about an evacuation destination for many northern Vietnamese at the time, opens up a world where people of different ethnic minorities mingled, where the mountains and forests of the country's northeastern region raged on, and where many threatened species listed in the International Union for Conservation of Nature (IUCN) Red List such as tiger and pheasants roamed about (Nguyen, 1974). This is just one in the treasure trove of children's books published in the 1960s-70s about the grandeur of Vietnamese nature, which includes "Đảo Hoang" (lit. "Deserted Island") by To Hoai (published in 1969), and "Thú Rùng Tây Nguyên" (lit. "Wild species of Central Highlands forests") by Thien Luong (in 1975), etc. Even the Vietnamese children who were born into big cities like Hanoi during that era had grown up with a certain sense of pride about its urban green space as well as the historic Old Quarter, where unique signs of cultural transmission and evolution remain today (Vuong et al., 2019).

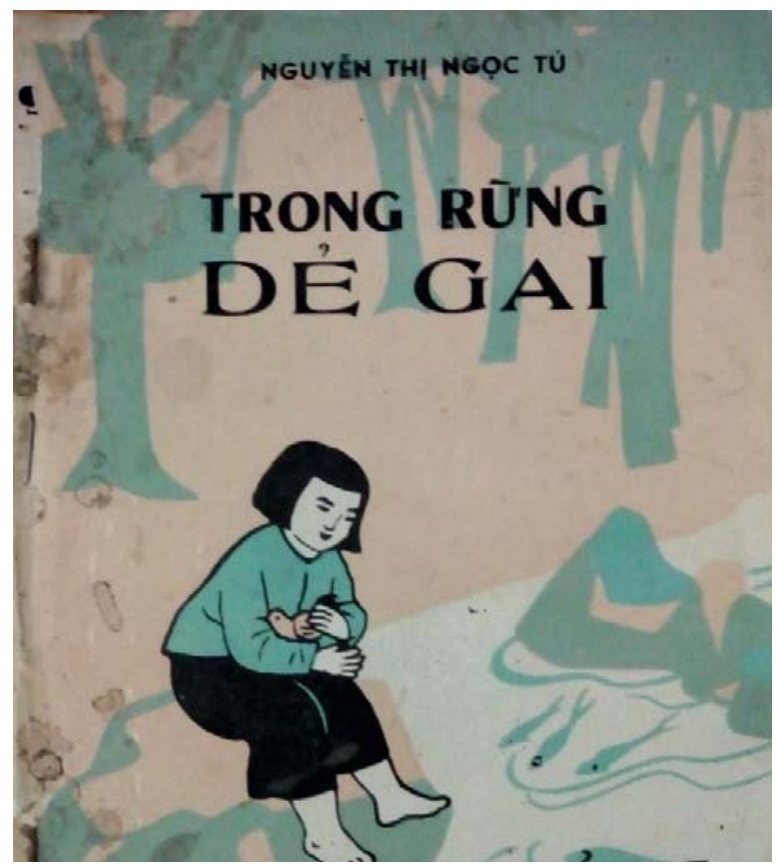

Figure 1. The cover of the book "Trong Rùng Dẻ Gai" written in 1974 by the late Vietnamese writer Nguyen Thi Ngoc Tu (1942-2013).

\footnotetext{
${ }^{1}$ The scientific name of the tree is Fagus sylvatica, and in general, it is often called the European beech or common beech, a deciduous tree belonging to the beech family Fagaceae.
} 
Children's literature reveals more than what it appears to tell. It is an important -- if not indispensable -- window, through which a generation would come to see different facets of life and human nature. I am fortunate or unfortunate enough to be one in those generations. Growing up in the mid-1970s, when the B52 bombing had become the past, my memories are a reflection of the images of a Hanoi where the Franco-Chinese houses (Vuong et al., 2019) hid among the lush greenery of big old trees.

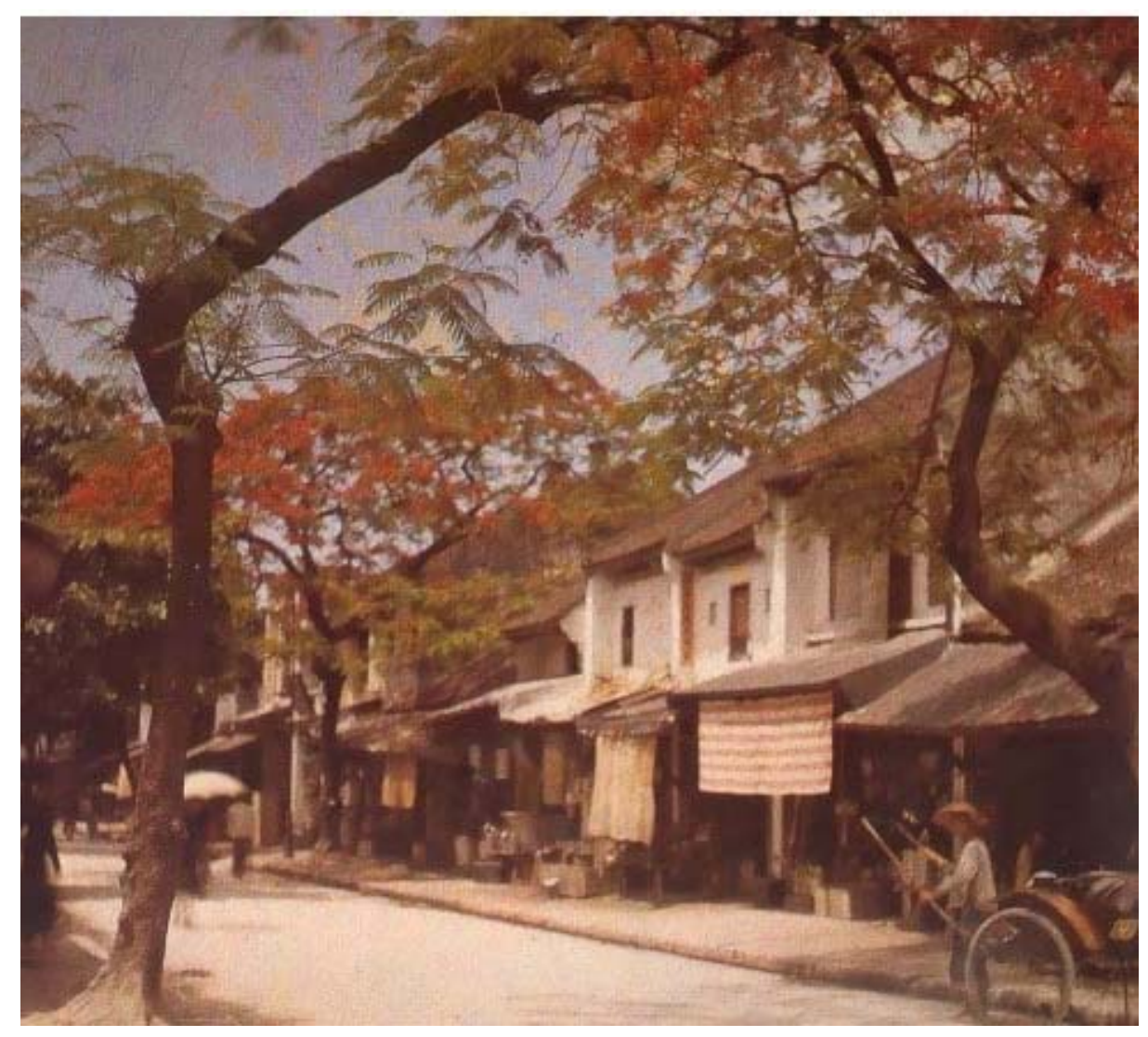

Figure 2: Hanoi in my memories.

Over the past decades, due to rapid urbanization and industrialization, many of the images portrayed in these books - the lustrous forests, the dancing animals, the pristine mountains, and waters have gradually withered. Deforestation and illegal logging first emerged as a major problem in Vietnam during the 1980s-90s (FAO, 2001), and mismanagement of forests has continued to plague mountainous regions in poverty (McElwee, 2016; Meyfroidt \& Lambin, 2008). The beauty of Vietnamese nature, as a generation once knew, is now in danger, and the age-old stories that are worth passing on have become little more than ancient artifacts - to be reminisced of rather than to be experienced again.

This picture of Vietnam stands in contrast to that of an economic miracle the country is often hailed for. Vietnam has indeed successfully shed its war-torn past and food insecurity as one of the 
poorest in the world to becoming a lower middle-income country. Yet, there are costly prices paid for the rapid economic development, and its nature and natural resources are those casualties. As the future of human development increasingly hinges on the need for sustainable education and science, this essay zooms out at the imminent threats to humankind and the relevance of achieving the United Nations' Sustainable Development Goals (SDGs) to science-technology research among today's young scientists. It also discusses some socio-political and economic aspects of sustainability and concludes with a proposal for developing sustainable science.

\section{Planet habitability, SDGs, and sustainability science research}

"...that tripod of theoretical cataclysms that have been felt to force disturbances deep down in the foundations of the "exact sciences." The three discoveries appear to deliver us into an unfamiliar world, one so at odds with our previous assumptions and intuitions

that, nearly a century on, we are still struggling to make out where, exactly, we have landed [...] Godel's incompleteness theorems. Einstein's relativity theories. Heisenberg's uncertainty principle." — Rebecca Goldstein (2006) in Incompleteness: The Proof and Paradox of Kurt Gödel.

As philosopher Rebecca Goldstein has rightly observed, it is true that with advances in science, the world is propelled into a time where things are speedier and more uncertain than any period in human history. It has been a little over ten years since the United States National Aeronautics and Space Administration (NASA) launched its Kepler Mission in March 2009 with the purpose of finding potentially habitable planets orbiting other stars like our Sun (NASA, 2017). The mission, which discovered 2,662 exoplanets during its nine-year service, many of which could be habitable (NASA, 2018), rekindled our hope for evidence of life beyond Earth as well as awakened our collective imagination by turning some of the most far-fetched and abstract notions into identifiable remote destinations (Batalha, 2018). Concrete evidence of an Earth-like planet has not surfaced despite hundreds of millions of dollars being spent, leaving Earth as the only habitable planet to date.

Perhaps, the hope for a habitable planet or the dream to colonize Mars comes from the depressing reality that we are currently living. In Collapse, Diamond (2005) suggested that two main causes for the fall of past civilizations are the destructive tendency towards our own kind and the environment. Every day, the media covers death from terrorist attacks, gun violence, traffic accident, or even death from overwork. Meanwhile, humanmade fire, plastic, and waste continue to destroy nature and wildlife; the 
climate has been producing more extreme weather patterns and severe natural disasters in response. It is hard to not think about the end (Franzen, 2019).

Given that we do not have a viable option of human habitability beyond Earth and that life on Earth is under serious threats, there is an urgent need to abide by a course of actions aimed at achieving the 17 SDGs (Figure 3). It is clear that the development of science and technology is the underlying critical factor to meeting these goals, from eliminating poverty (SDG1), hunger (SDG2), ensuring good health and well-being (SDG3), building infrastructure (SDG9), and bringing about clean water-sanitation (SDG6) and clean energy (SDG7), to name a few. Additionally, SDG4, which outlines the need for inclusive and equitable quality education for all, would lay the ground for science education and research in children and teachers at a global level. The UNESCO 2019 Forum on Education for Sustainable Development and Global Citizenship, which was hosted by Vietnam in July 2019, provides a venue to reflect on the policies and steps toward achieving the SDGs (MDPI, 2019).

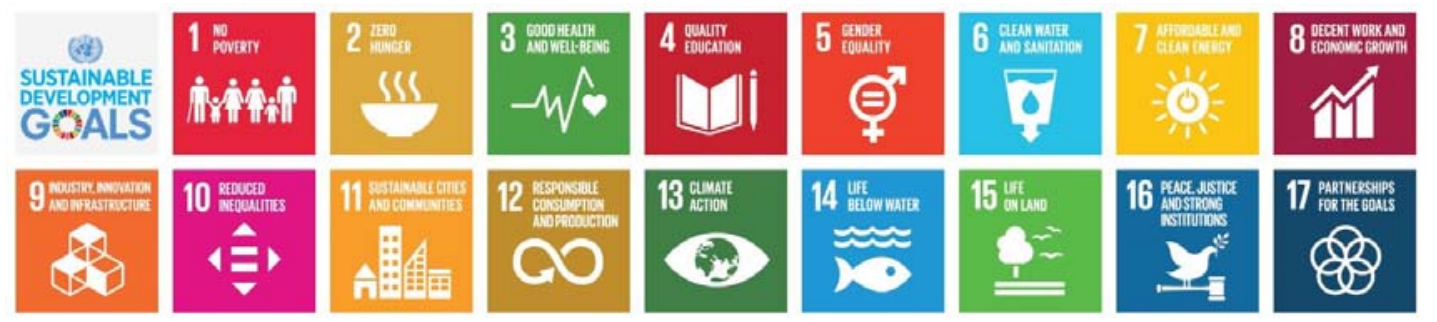

Figure 3. A summary of the 17 SDGs, adopted by all UN Member States in 2015

(Source: https://sustainabledevelopment.un.org/sdgs)

Much of this is indubitably obvious. The lofty goals presented and discussed numerous times by the media and academia have become nothing more but cliché talking points, making the public oversaturated with topics that ought to be taken seriously in their own rights. Perhaps the more worrying turn is how even policymakers in the world's leading nation, the United States, have turned to attack the scientific community and questioning the value of scientific research (Tollefson, 2018; Vuong, 2018). In 2017, the administration under U.S. President Donald Trump effectively withdrew from the Paris Agreement on climate change mitigation and later disbanded a government advisory committee for climate science (Tollefson, 2017). In one of the latest developments that are counter to the scientific spirit, on November 11, 2019, the New York Times reported that the Trump administration has drafted a proposal under which the Environmental Protection Agency (EPA) would require scientists to disclose all of their raw data, including confidential medical records, in order for EPA to validate an academic study's 
conclusions (Friedman, 2019). The draft bill threatens to reverse the admissibility of many landmark studies - such as one that proves a link between mercury from power plants and brain impairment (Trasande, Landrigan, \& Schechter, 2005) or a correlation between paint dust exposure and children's behavior disorders (Liu et al., 2014) - because personal data were used and could not be disclosed. These challenges in socio-political and economic terms present considerable barriers to achieving sustainability, not just in science but also for humanity as a whole.

\section{Light of hope}

Not all hopes have been lost, fortunately. There continue to be numerous contributions to building and sustaining a better life on Earth by policymakers, scientists, activists, and individuals across continents. If on one side of the planet where the United States no longer champions climate science and sustainability as critical issues, then on the other side, a city in Japan, Kitakyushu, is known for adopting environment-friendly industrial policies since 1967 (Low, 2013). One of our latest studies on this case examines the impacts of green growth policies on air pollutant reduction and industrial growth in Kitakyushu city, in the belief that there are valuable lessons for developing and developed economies alike (Vuong, Ho, Nguyen, \& Nguyen, forthcoming in 2019). Furthermore, our lab's collaboration with IUCN has resulted in ongoing research about Vietnamese business and their engagement with environmental preservation and protection. By scanning the news on environment and business from Vietnamese news outlets, preliminary findings suggested a high level of involvement of businesses from manufacturing, logistic, agriculture, and environment industry in environmental-damaging scandals. Besides our own works, other Vietnamese scholars have also explored the relationship between the environment and society. Pioneering works are from senior scholars such as Vo Tong Xuan (Dapice \& Xuan, 2012; Pingali \& Xuan, 1992; Xuan, 1995), or Tran Duc Vien (Rambo \& Tran, 2001; Tran, 2003, 2011), who have done research on the social aspects of agriculture and human impact to sustainability.

Some of the aforementioned examples highlight the need to be patient, to maintain scientific integrity and trust in the scientific enterprise, and to reframe our approaches to the multifaceted issues of sustainability. There is indeed light to be seen at the end of every scientific inquiry, however improper it may appear. On November 11, 2019, the media reported that a deer-like animal - the silver-backed chevrotain Tragulus versicolor (Figure 4) - has been found again in the wild in Vietnam for the first time in 30 years (Ho, 2019; Nguyen et al., 2019; Nogrady, 2019). The rediscovery was all the more remarkable because, just when the research team, comprised of many experts at IUCN, had thought finding this species would be unlikely due to the lack of documentation or recent detection, they received help from the local people near Nha Trang forests (Nogrady, 2019). With camera traps in the forests, they were able to capture the image of a once lost species, giving many of us Vietnamese for the first time photographic 
evidence of a cheo cheo, a creature so endearingly drawn on the cover of the 1975 classic book "Thu' Rùng Tây Nguyên" (lit. "Wild species of Central Highlands forests") (Figure 5). The finding not only confirms the beauty of scientific discovery and collaboration but also ignites hopes for biodiversity conservation today.

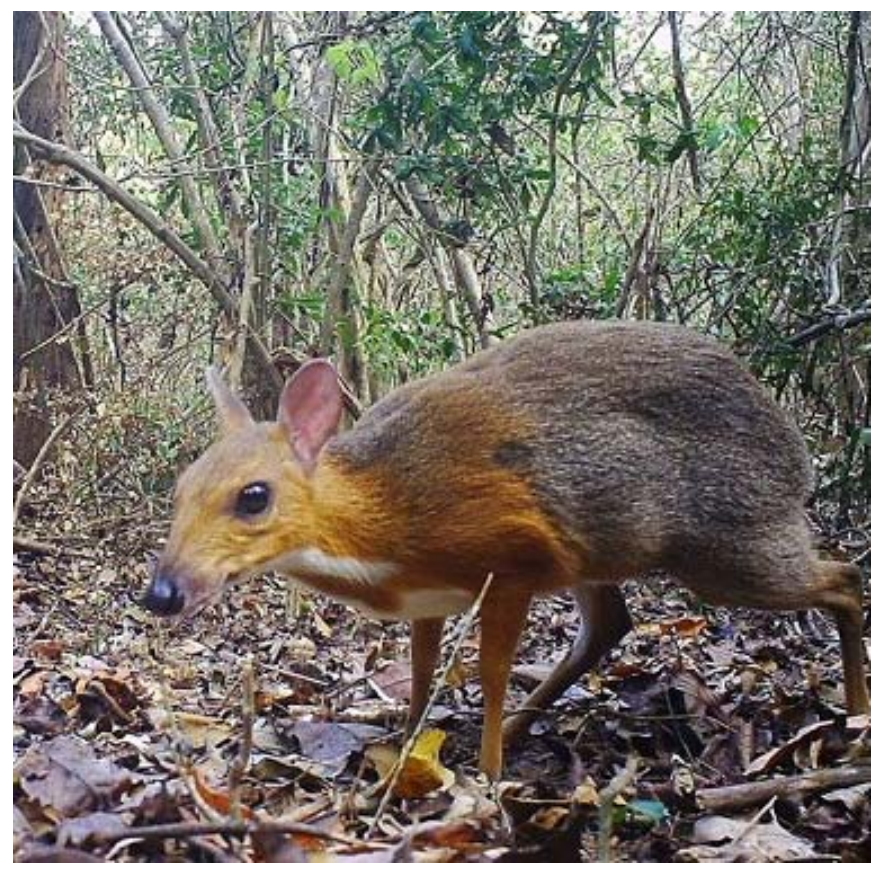

Figure 4. A photo of a Cheo cheo lung bac (silver-backed chevrotain Tragulus versicolor) that was recently re-discovered in Vietnam (Source: SIE/GWC/Leibniz-IZW/NCNP on Nature at https://www.nature.com/articles/d41586-019-03467-7) 


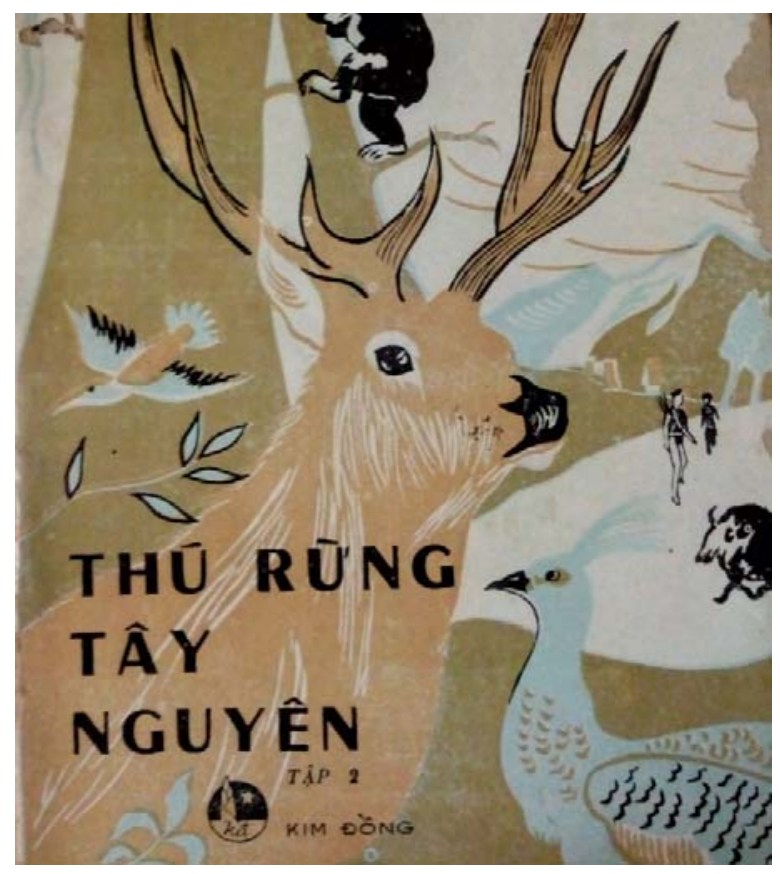

Figure 5. The cover of the book "Thú Rùng Tây Nguyên" (lit. "Wild Species of the Central Highlands Forests") published by Kim Dong Publishing House in 1975.

Going beyond the academic realm, there are also hopes from the business community. Here are some notable initiatives toward sustainable science and the environment from Vietnam. First, IUCN Vietnam has launched a number of initiatives to support the strategic development of the Vietnam Business for Environment (VB4E) (IUCN, 2019). VB4E aims to engage Vietnamese businesses in the process of pursuing sustainable development, which will protect us from the seemingly inevitable fate that Jared Dimond discussed (Diamond, 2005). Our team members are honored to support IUCN in finding a suitable approach for VB4E.

Second, Phenikaa University, Hanoi, and its Phenikaa Innovation Foundation are constantly advocating for a scientific environment that inspires innovation and "responsible creativity." The term "responsible creativity" was coined by Chairman Dang Le Nguyen Vu of Trung Nguyen Coffee, a leading Vietnamese business in the coffee industry, in his proposal to the ASEAN Secretariat and United Nations Academic Impact in 2012 (Napier, 2012; Napier \& Vuong, 2013).

\section{Youth engagement with scientific research}

"We small guys sleep on narrow beds Our small dreams crush our little fates." 
— Che Lan Vien (1960), translated by Napier and Vuong (2013).

A sustainable future cannot be without the input of the youth. Recently, the world has heard the voices of climate activist such as Greta Thunberg or Jamie Margolin (Marris, 2019). And in every corner of the world, there are young people who determine to leverage their scientific mindset into building sustainable businesses. There are young scientists who aspire to master the methods and tools of modern science to solve the world's problems. Indeed, in the constant battle to find solutions to local and global problems, the input of young, competent, creative, and idealistic minds is absolutely a resource the world cannot do without. Young philosophers and researchers such as William MacAskill, Benjamin Todd, and Toby Ord have successfully pushed forward the prime agendas of the effective-altruism movement by founding and running multiple foundations that direct global resources toward charity that has saved the most lives, or help people to choose career that will maximize their altruistic impacts in the world, or conduct basic research on the questions of global priorities (MacAskill, 2018; MacAskill, Mogensen, \& Ord, 2018). Effectively, the works of these young scholars have revolutionized how people think about philanthropy, charity, and career choice. In other words, I would argue, they have nudged people toward a more sustainable way of conceptualizing these traditional activities.

Meanwhile, myopic conceptions of sustainability can cause real damages to the world. For example, one of the influential misleading conception of the concept, especially in business circles, is sustainable business equals long-term profit. This view has directly translated some businesses had dealt with environmental resources, such as the cases of Hoang Anh Gia Lai (HAGL) or A Cuong Mineral Group (ACM) are the prime examples (Hodal \& Kelly, 2013; IDI, 2019; Linh, 2015; Mai, 2019). There are many reasons for their financial struggles, but mindless deforestation and illegal waste dumping are certainly among the contributing factors.

The example of the young philosophers above epitomizes the spirit of academic entrepreneurship (Glassman et al., 2003): being able to create and seize opportunities within an academic setting in spite of available resources. This is an important area, often overlooked by both the media, the academia, and perhaps even the young scientists as well. The father of quantum computation, physicist David Deutsch has famously pointed out that people often confuse sustainability with a branch of resource management science, while, the true essence of being sustainable is being able to solve problems regardless of available resources, which requires the ability to innovate and a culture of criticism (Deutsch, 2011). In a recent article on the sustainability of research networks, the authors, following (Deutsch, 2011), suggest sustaining scientific communities, which are productive and innovative, is the way forward in the constant 
battle in building a sustainable future (Ho, Nguyen, Vuong, \& Vuong, 2017). Building such scientific communities requires nurturing youth engagement with science and the scientific mindset.

It is clear when young people are properly equipped with a scientific mindset, with the right entrepreneurial attitude, there is no shortage of problems they can confront to move the world into a sustainable future. Since 2018, based on the national project of collecting and analyzing data on scientific productivity of Vietnamese social scientists (Vuong et al., 2018), we have created a scientific communication platform (https://sc.sshpa.com), the first of its kind in Vietnam, where we summarized and introduced publications of Vietnamese scholars worldwide in Vietnamese language. The hope is that this community can help engage and nurture the young minds with big, daring dreams for science, and a sustainable future, as nowadays, doing science means one cannot avoid sustainability.

\section{Acknowledgment:}

I want to thank my research team members, namely Nguyen T. Hong Kong, Ho Manh Tung, La Viet Phuong, Nguyen Minh Hoang, Ho Manh Toan, and Vuong Thu Trang. They are the raison d'être of this whole research program, and more importantly, for me, they represent the future of science, and the sustainability thereof.

\section{References}

Batalha, N. M. (2018). A Planet for Goldilocks: The Search for Evidence of Life Beyond Earth. Paper presented at the 5th USA Science \& Engineering Festival Expo; April 07, 2018 - April 08, 2018, Washington, DC.

Dapice, D., \& Xuan, V. T. (2012). The Mekong Delta: Rural Development Meets the EnvironmentSystemic Challenges and Possible Solutions. Journal of Macromarketing, 32(1), 147-151. doi:10.1177/0276146711426433

Deutsch, D. (2011). The beginning of infinity: Explanations that transform the world. London, UK: Penguin UK.

Diamond, J. (2005). Collapse: How societies choose to fail or succeed. London, UK: Penguin Books.

FAO. (2001). Global Forest Resources Assessment, 2000. Retrieved from Rome:

Franzen, J. (2019). What If We Stopped Pretending? Retrieved from https://www.newyorker.com/culture/cultural-comment/what-if-we-stopped-pretending

Friedman, L. (2019). E.P.A. to Limit Science Used to Write Public Health Rules. Retrieved from https://www.nytimes.com/2019/11/11/climate/epa-science-trump.html 
Glassman, A. M., Moore, R. W., Rossy, G. L., Neupert, K., Napier, N. K., Jones, D. E., \& Harvey, M. (2003). Academic entrepreneurship: Views on balancing the Acropolis and the Agora. Journal of Management Inquiry, 12(4), 353-374.

Goldstein, R. (2006). Incompleteness: The Proof and Paradox of Kurt Gödel (Great Discoveries). New York: WW Norton \& Company.

Ho, M.-T. (2019). Cheo cheo lưng bạc Việt Nam được giới khoa học tái phát hiện [Silver-backed chevrotain in Vietnam rediscovered by scientists]. Retrieved from https://sc.sshpa.com/post $/ 5580$

Ho, M. T., Nguyen, K. T. H., Vuong, T.-T., \& Vuong, Q.-H. (2017). On the Sustainability of CoAuthoring Behaviors in Vietnamese Social Sciences: A Preliminary Analysis of Network Data. Sustainability, 9(11). doi:10.3390/su9112142

Hodal, K., \& Kelly, C. (2013). Deutsche Bank and IFC accused of bankrolling Vietnam firms' land grabs. Retrieved from https:/www.theguardian.com/world/2013/may/13/deutsche-bank-ifc-bankrollvietnam-cambodia-laos

IDI. (2019). Cambodian indigenous communities win back their sacred land from Vietnamese rubber developer. Retrieved from https://www.inclusivedevelopment.net/cambodian-indigenouscommunities-win-back-their-sacred-land-from-vietnamese-rubber-developer/

IUCN. (2019). Call for Consultant: Stock-taking of business engagement initiatives on environment protection in Viet Nam. Retrieved from https:/www.iucn.org/news/viet-nam/201905/callconsultant-stock-taking-business-engagement-initiatives-environment-protection-viet-nam

Linh, G. (2015). Công ty Á Cường bị đình chỉ sản xuất và yêu cầu khắc phục ô nhiễm môi trường [A Cuong Mineral Group was prohibited from mining and needed to solve the environmental pollution]. Retrieved from http://tapchimoitruong.vn/

Liu, J., Liu, X., Wang, W., McCauley, L., Pinto-Martin, J., Wang, Y., . . . Rogan, W. J. (2014). Blood Lead Concentrations and Children's Behavioral and Emotional Problems: A Cohort Study. JAMA Pediatrics, 168(8), 737-745. doi:10.1001/jamapediatrics.2014.332

Low, M. (2013). Eco-cities in Japan: past and future. Journal of Urban Technology, 20(1), 7-22. doi:10.1080/10630732.2012.735107

MacAskill, W. (2018). Understanding Effective Altruism and Its Challenges. In D. Boonin (Ed.), The Palgrave Handbook of Philosophy and Public Policy (pp. 441-453). Cham: Springer International Publishing.

MacAskill, W., Mogensen, A., \& Ord, T. (2018). Giving Isn't Demanding The Ethics of Giving: Philosophers' Perspectives on Philanthropy (pp. 178). Oxford: Oxford University Press. 
Mai, T. (2019). Khoáng sản Á Cường (ACM) lại "khất" trả cổ tức lần thứ 7 [A Cuong Mineral Group has delayed paying the dividend for the 7th time]. Retrieved from http://cafef.vn/khoang-san-acuong-acm-lai-khat-tra-co-tuc-lan-thu-7-20190626112921593.chn

Marris, E. (2019). Why young climate activists have captured the world's attention. Nature, 573, 471-472. doi:10.1038/d41586-019-02696-0

McElwee, P. (2016). Forests are Gold: Trees, People, and Environmental Rule in Vietnam. Seattle: University of Washington Press.

MDPI. (2019). Special Issue "Academic Contributions to the UNESCO 2019 Forum on Education for Sustainable Development and Global Citizenship". Retrieved from https://www.mdpi.com/journal/sustainability/special issues/UNESCO 2019

Meyfroidt, P., \& Lambin, E. F. (2008). Forest transition in Vietnam and its environmental impacts. Global Change Biology, 14(6), 1319-1336. doi:10.1111/j.1365-2486.2008.01575.x

Napier, N. K. (2012). What's Small, Tasty, and May Change the World? Retrieved from https://www.psychologytoday.com/intl/blog/creativity-without-borders/201205/whats-smalltasty-and-may-change-the-world?amp

Napier, N. K., \& Vuong, Q. H. (2013). What we see, why we worry, why we hope: Vietnam going forward. Boise, Idaho: Boise State University CCI Press.

NASA. (2017). Liftoff of the Kepler spacecraft. Kepler and K2. Retrieved from https://www.nasa.gov/mission_pages/kepler/launch/index.html

NASA. (2018). NASA Retires Kepler Space Telescope, Passes Planet-Hunting Torch. Retrieved from https://www.nasa.gov/press-release/nasa-retires-kepler-space-telescope-passes-planet-huntingtorch

Nguyen, A., Tran, V. B., Hoang, D. M., Nguyen, T. A. M., Nguyen, D. T., Tran, V. T., ... Tilker, A. (2019). Camera-trap evidence that the silver-backed chevrotain Tragulus versicolor remains in the wild in Vietnam. Nature Ecology \& Evolution, 3(12), 1650-1654.

Nguyen, T. N. T. (1974). Trong Rùng Dẻ Gai [In the Hazlenut Forest]. Hanoi: NXB Kim Đồng.

Nogrady, B. (2019). Elusive deer-like animal 'rediscovered' in Vietnam. Nature News. Retrieved from https://www.nature.com/articles/d41586-019-03467-7

Pingali, P. L., \& Xuan, V.-T. (1992). Vietnam: Decollectivization and Rice Productivity Growth. Economic Development and Cultural Change, 40(4), 697-718. doi:10.1086/451973

Rambo, A. T., \& Tran, D. V. (2001). Social Organization and the Management of Natural Resources A Case Study of Tat Hamlet, a Da Bac Tay Ethnic Minority Settlement in Vietnam's Northwestern Mountains. 東南アジア研究, 39(3), 299-324. doi:10.20495/tak.39.3_299 
Tollefson, J. (2017). US government disbands the climate-science advisory committee. Nature News. Retrieved from https://www.nature.com/news/us-government-disbands-climate-science-advisorycommittee-1.22484

Tollefson, J. (2018). Science under siege: behind the scenes at Trump's troubled environment agency. Nature News. Retrieved from https://www.nature.com/articles/d41586-018-05706-9

Tran, D. V. (2003). Culture, Environment, and Farming Systems in Vietnam\&apos;s Northern Mountain Region. 東南アジア研究, 41(2), 180-205. doi:10.20495/tak.41.2_180

Tran, D. V. (2011). Climate change and its impact on agriculture in Vietnam. Journal of ISSAAS, 17(1), $17-21$.

Trasande, L., Landrigan, P. J., \& Schechter, C. (2005). Public health and economic consequences of methyl mercury toxicity to the developing brain. Environmental Health Perspectives, 113(5), 590-596. doi:10.1289/ehp.7743

Vuong, Q.-H. (2018). The (ir)rational consideration of the cost of science in transition economies. Nature Human Behaviour, 2(1), 5-5. doi:10.1038/s41562-017-0281-4

Vuong, Q.-H., Bui, Q.-K., La, V.-P., Vuong, T.-T., Ho, M.-T., Nguyen, H.-K. T., . . Ho, M.-T. (2019). Cultural evolution in Vietnam's early 20th century: A Bayesian networks analysis of Hanoi Franco-Chinese house designs. Social Sciences \& Humanities Open, 1(1), 100001. doi:https://doi.org/10.1016/j.ssaho.2019.100001

Vuong, Q.-H., Ho, M.-T., Nguyen, H.-K. T., \& Nguyen, M.-H. (2019). The trilemma of sustainable industrial growth: Evidence from a piloting OECD's Green city. Palgrave Communications, 5 (article in press); doi:10.1057/s41599-019-0369-8

Vuong, Q.-H., La, V.-P., Vuong, T.-T., Ho, M.-T., Nguyen, H.-K. T., Nguyen, V.-H., ... Ho, M.-T. (2018). An open database of productivity in Vietnam's social sciences and humanities for public use. Scientific Data, 5(1), 180188. doi:10.1038/sdata.2018.188

Xuan, V.-T. (1995). Rice production, agricultural research, and the environment. In B. J. T. Kerkvliet (Ed.), Vietnam's Rural Transformation (pp. 185-200). Abingdon, UK: Routledge. 